\title{
Rafael María de Labra ante la cuestión de Cuba, 1898
}

\author{
M. ${ }^{a}$ Dolores Domingo Acebrón
}

Centro de Estudios Históricos, CSIC. Madrid

Rafael M. ${ }^{a}$ de Labra fue uno de los intelectuales del siglo XIX más sensibilizados por el problema colonial y principalmente por la cuestión de Cuba. La lucha infatigable de Labra por conseguir reformas políticas para las dos últimas colonias, Cuba y Puerto Rico, su defensa del sistema político autonomista y el respeto y tolerancia hacia los revolucionarios cubanos le valdría incluso, después de la independencia de Cuba en 1898, el reconocimiento moral de la nueva nación.

Rafael M. ${ }^{a}$ de Labra es uno de los intelectuales del siglo XIX más preocupado por lo que se denominaba como la cuestión colonial, o la "cuestión de Cuba", en una época crucial para España como fue 1898, que supuso la pérdida de las dos últimas colonias en América, Cuba y Puerto Rico.

El interés de Labra por la cuestión de Cuba fue palpable a través de su labor parlamentaria, como diputado y senador, y asimismo fuera del Parlamento, en instituciones de reconocido prestigio intelectual, como

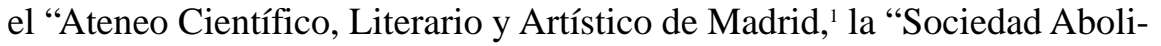
cionista Española", ${ }^{2}$ el "Fomento de las Artes", ${ }^{3}$ la "Unión Iberoamericana" o la "Casa de América" de Barcelona, entre otras.

\section{Acción parlamentaria y la defensa de las reformas para Cuba}

La actividad parlamentaria de Labra fue muy intensa durante cerca de cuarenta años, siempre en favor de las mismas ideas políticas y sociales

1 Rafael M. a de Labra se convertiría en el historiador del Ateneo como autor de dos de sus más importantes obras: El Ateneo de Madrid. Sus orígenes, desenvolvimiento, representación y porvenir. Madrid, Imprenta de Aurelio J. Alaria, 1878, y El Ateneo de Madrid (1835-1905). Notas Históricas. Madrid, Tipografía de Alfredo Alonso, 1906.

2 Labra fue elegido en 1869 como presidente de la Sociedad Abolicionista Española fundada en 1865 por Julio Vizcarrondo, con el apoyo de importantes personalidades del liberalismo, de la cual será Vizcarrondo su infatigable secretario. Morales Carrión, Arturo: "Las corrientes abolicionistas en Puerto Rico". Anuario de Estudios Americanos, Sevilla, 1986, vol XLIII, pág. 302.

3 Labra fue presidente honorario de dicha asociación que había sido fundada en 1852, y que llegaría a convertirse en la primera sociedad de educación popular de España, la cual impulsará notablemente las reformas pedagógicas. Labra, Rafael M. ${ }^{a}$ : La acción particular en el movimiento pedagógico de la España contemporánea. Discurso pronunciado en el banquete que se celebró el 19 de noviembre de 1892 en el restaurante Rusia de Madrid. Labra, Rafael M. ${ }^{\text {a: }}$ El Congreso Pedagógico Hispano-Americano de 1892. Madrid, Librería de la Viuda de Hernando y C. ${ }^{\text {, }}$ 1893, pág. 321. 
y en defensa de la personalidad internacional de España, seriamente dañada por la política colonial durante todo el siglo XIX. ${ }^{4}$

Desde su primer discurso parlamentario en 1872, en representación de los liberales y reformistas, hasta su discurso autonomista de 1880 será alentado por sus amigos cubanos en el Congreso, hombres como Calixto Bernal, José Ramón Betancourt o José Güell y Renté. Labra es, sin duda, el hombre que representa a los autonomistas, y es, sobre todo, uno de los políticos españoles más sensibilizados por la "cuestión antillana". La abolición de la esclavitud se convierte para Labra en una "obsesión". Paulatinamente, se irá preocupando por la dignificación del español antillano y por la igualdad civil y política en este y en el otro lado del Atlántico. A partir de 1879 se dedica fundamentalmente a defender mediante la propaganda y la realización de gestiones directas la necesidad de instaurar la autonomía colonial. ${ }^{5}$

En sus campañas parlamentarias y extraparlamentarias, desde 1879 hasta 1900, destacan sobre todo dos cuestiones: el abolicionismo y el autonomismo en el orden colonial, sobre las bases de los derechos políticos y civiles de españoles y antillanos, de toda clase y color, y de la representación parlamentaria de las Antillas en el Congreso.

Su discurso del 4 de julio de 1880 en el Congreso en nombre de la minoría parlamentaria, sobre "El Primer Presupuesto de Cuba", plantea la primera reclamación de la autonomía colonial y práctica para las Antillas. El último discurso que pronuncia en el Senado, el 30 de junio de 1896, es la última protesta de los autonomistas "desheredados"; la última protesta de la propaganda autonomista en la oposición, convirtiéndose Labra en el único representante de los dos partidos autonomistas de las Antillas. ${ }^{6}$

\section{La cuestión de Cuba, 1898}

Uno de los acontecimientos históricos más importantes y que llevaron a Labra a una reflexión profunda sobre la "cuestión de Cuba" fue el comienzo de la guerra en 1895. En ese año Labra ostentaba el puesto de

4 Domingo Acebrón, M. ${ }^{a}$ Dolores: Rafael M. ${ }^{a}$ de Labra. Antología del Pensamiento político, social y económico español sobre América Latina. Madrid, 1997.

5 Labra, Rafael M.': La crisis colonial de España (1868-1898). Estudios de Política palpitante y discursos parlamentarios. Madrid, Tipografía de Alfredo Alonso, 1901, pág. 5.

6 Labra, Rafael M. a : Los Partidos en Las Antillas. Discurso en el Congreso de los Diputados el 7 de julio de 1891. Labra, Rafael M. a : La Autonomía colonial en España. Discursos. Madrid, Imprenta de los Sucesores de Cuesta, 1892, págs. 85-90. 
senador, después de haber sido elegido con el apoyo de la Universidad de La Habana y del Partido Autonomista cubano. El 30 de mayo pronuncia un discurso en el cual queda de manifiesto su posición ante este nuevo conflicto. En primer lugar, aborda la gravedad de la situación en el orden interno e internacional, debido a la guerra de Cuba; en segundo lugar, solicita a los partidos gubernamentales de la península que realicen una declaración en favor de la pacificación de Cuba y del futuro político y social, y en tercer lugar, ratificaba los compromisos con el Partido Autonomista Cubano en pro de la bandera española y de la pacificación de la isla. Según Labra:

"no sólo España tenía el derecho a conservar Cuba, como parte integrante de la Nación como lo son las playas de Andalucía, los llanos de Castilla y las playas de Cataluña. Además creía y creo que España tiene el deber de dominar pronto y bien la insurrección separatista, por la ley del honor en beneficio de la complicada sociedad antillana, por el interés del derecho internacional contemporáneo y en cumplimiento de los trascendentales y prestigiosos compromisos de los grandes pueblos colonizadores"?

El problema cubano no era para él una cuestión de política nacional, sino un problema de política internacional, por las implicaciones que provocó y por la posición de Estados Unidos ante el conflicto, con el reconocimiento de beligerancia a los rebeldes cubanos. ${ }^{8}$

Labra consideraba a los Estados Unidos como la gran patria de Washington, Lincoln y Monroe, y fue una decepción para un demócrata reflexivo y convencido republicano — como el mismo se definía - el atropello de los principios y reglas del Derecho internacional contemporáneo, los cuales perjudicarían al prestigio internacional de la joven república y a la paz y al progreso del mundo.

El mensaje del presidente McKinley de 6 de diciembre de 1897 exponía el apoyo que tenían del mundo civilizado para intervenir por la fuerza en la cuestión de Cuba, "si así lo imponían la civilización, la humanidad y los intereses de los Estados Unidos”. El Congreso había determi-

7 Ibídem, pág. 133.

8 Estados Unidos en la Guerra de los Diez Años había negado el reconocimiento de beligerancia a los independentistas cubanos, presionado por las autoridades españolas, las cuales amenazaban con aplicar el Tratado de Amistad, Límites y Navegación firmado entre España y Estados Unidos en 1795. Por el contrario en 1895 la situación había cambiado y Estados Unidos reconoció la beligerancia y la lucha de los revolucionarios cubanos. Domingo Acebrón, M. ${ }^{a}$ Dolores: "El Reconocimiento de beligerancia y la posición de Estados Unidos en la Guerra de los Diez Años, 1868-1878”. En Actas de las Jornadas sobre América Latina, Sevilla, 1998 (en prensa). 
nado la expulsión inmediata de España de Cuba. Y además el mismo había atribuido el derecho a hacer entrar en el concierto del mundo contemporáneo a un pueblo libre e independiente, y había fijado incluso la hora y el modo como debía hacerse.

El presidente norteamericano señalaba los perjuicios más importantes de la guerra de Cuba, entre los que destacaba la imposibilidad del gobierno español para proteger a los ciudadanos norteamericanos y sus intereses allí, los numerosos gastos provocados por las expediciones con armas a la isla y los problemas de los barcos que podían ser apresados por la marina extranjera.

Labra era consciente de que tanto McKinley como Cleveland habían considerado la anexión de Cuba como algo fundamental para los Estados Unidos, que sólo era una cuestión de tiempo, teniendo Estados Unidos el papel de redentor y no el de país agresor. Incluso Cleveland incitaba a las autoridades españolas para que realizaran las reformas necesarias y, en definitiva, una política de pacificación en la situación de guerra en la cual se encontraba. Sin embargo, Mc Kinley optó por una política de expansión colonial e imperialista.

Labra, en una reflexión profunda sobre la guerra hispanoamericana, exponía el interés internacional que ésta suponía y lo que representaba para España:

"es mucho, muchísimo más que el reducido interés de poseer las Antillas y las Filipinas, mucho muchísimo más que su aspiración legítima, pero apenas comprendida por la casi totalidad de nuestros actuales hombres políticos, a ser una gran personalidad en el mundo contemporáneo, mediante un cambio profundo en su manera de ser y en sus relaciones coloniales e internacionales". ${ }^{9}$

La guerra del 98 termina con el dominio colonial español en Cuba. Pero lo que podría haber culminado con el proceso de liberación del pueblo cubano, quedó frustrado debido a la intervención de Estados Unidos en la guerra y las consecuencias que posteriomente se derivaron.

El interés de Estados Unidos por anexionarse Cuba tuvo una negativa bastante rotunda del pueblo cubano, pero la "Enmienda Platt" fue la fórmula ideal para el imperialismo norteamericano; el 21 de febrero de 1901 se sancionó la constitución de la nueva República, y el 12 de junio dicha

9 Labra, Rafael M.' : Aspecto internacional de la cuestión de Cuba. Madrid, Tipografía de Alfredo Alonso, 1900 
Enmienda, como apéndice constitucional, quedando de este modo legalizada la dependencia neocolonial del nuevo estado. ${ }^{10}$

\section{Labra y el proceso de independencia de Cuba}

Uno de los aspectos más importantes en el "problema cubano" era no olvidar que los revolucionarios cubanos - y numerosos españoles ${ }^{-11}$ aglutinados en el Ejército Libertador pretendían conseguir la independencia de Cuba del colonialismo español.

La posición de Labra ante la independencia de Cuba en 1898 fue bastante tajante y clara: “...no he sido partidario de la independencia de nuestras Antillas", y defendía la perfecta compatibilidad de la autonomía de las colonias y la integridad nacional española.

Incluso unos años antes, en 1868, cuando comienza la Guerra de los Diez Años, Rafael M. ${ }^{a}$ de Labra era consciente de que la Revolución de Septiembre tendría que haber proclamado una serie de libertades en las colonias. Respecto a este tema la opinión pública internacional se hizo eco de cómo, a pesar de haberse producido algunos cambios importantes en la península - destronamiento de Isabel II, proclamación de la Primera República en 1873, entre otros-, Cuba continuaba sin obtener ningún tipo de reformas políticas.

El fracaso de la Junta de Información en 1866 fue el detonante para que algunos reformistas, todavía con esperanzas de que se produjeran algunos cambios, tomaran posiciones en favor de la independencia. ${ }^{12}$

10 Fernández Sosa, Mirian: "El intervencionismo norteamericano en Cuba y su reflejo en el pensamiento político cubano de principios del S. XIX”. Arbor, Madrid, 1993, n. ${ }^{\circ}$ 567, tomo CXLIV, pág. 119.

11 Los españoles, es decir los peninsulares afincados en la isla participaron activamente en la contienda por la liberación de Cuba. Sobre estos temas ver : Domingo Acebrón, M. ${ }^{a}$ Dolores: "La participación de españoles en el Ejército Libertador en Cuba, 1895-1898". Revista de Indias, Madrid, 1992, vol LII, n. ${ }^{\circ}$ 195-196, págs. 349-363. "Los españoles y su participación en la Guerra de independencia, 1898”, En La Nación Soñada: Cuba, Puerto Rico y Filipinas ante el 98. Madrid, 1996, págs. 647-661. La Participación de canarios en las Guerras de Independencia en Cuba, 1868-1898. Fuerteventura, 1998 (en prensa).

12 Por ejemplo, entre algunos de los integrantes antillanos llamados a Madrid para participar en la Junta de Información figuraban los reformistas José Antonio Echevarria, el conde de Pozos Dulces y José Morales Lemus. Entre ellos había bastante descontento puesto que se les denominaba "comisionados informantes" y no diputados. Lemus aplacaría el malestar diciendo: "vamos por última vez donde se nos llama por primera y donde si no se nos hace justicia no hemos de volver". Betancourt, José Ramón: Discursos y Manifiestos políticos. Madrid, Establecimiento Tipográfico de Felipe Pinto, 1887, págs. 279-295. 


\section{M. ${ }^{a}$ DOLORES DOMINGO ACEBRÓN}

"He condenado esa insurrección y he hecho todos los posibles para evitar sus progresos...Tengo la convicción profunda que sin esa insurrección la libertad se hubiera proclamado en Ultramar...Creía en fin, y hoy creo más que por el camino que vamos, que es el abierto en 1868, Cuba se pierde para España para la raza latina, si que (horror me causa decirlo porque yo he cifrado muchas esperanzas sobre nuestras Antillas), para la civilización".13

Idéntica posición fue la defendida por Labra en el Congreso de los Diputados en el inicio de la Guerra Chiquita (1879-1881); el discurso pronunciado en 1880 defendía la idea de que España sí podía conceder reformas de tipo liberal en Cuba, cuestión que era puesta en duda en los medios políticos.

El verdadero obstáculo de las reformas coloniales había sido la guerra, que adquirió enseguida tintes separatistas. Y volvía a manifestar:

"protesto desde el fondo de mi alma contra la guerra que de nuevo arde en una parte de Cuba; por eso felicito al partido liberal cubano que con tanta decisión trata de sofocar esa descabellada intentona.¡Paz! ¡Paz! Ésa es una de nuestras primeras armas”. ${ }^{14}$

En una entrevista concedida al periodista Luis Morote, que apareció publicada en El Heraldo de Madrid y en El Mundo de La Habana, volvía a resaltar como el problema cubano del 98 era de tipo internacional, y como éste había sido uno de los más graves y que más había pesado a la hora del resultado obtenido, además de la falta de una política internacional con los países europeos. Y si a esto sumamos la incomunicación oficial y la inexistencia de relaciones estrechas con el mundo intelectual europeo, todo ello había producido el aislamiento con el mundo exterior. Los principales causantes de esta situación habían sido los embajadores y los políticos, los cuales habían obstruido la proyección internacional cubana, principalmente en Europa. Para Labra

"la catástrofe colonial nunca se hubiera producido de existir en el alma nacional un criterio, una voluntad. Caíamos de tumbo en tumbo por no saber lo que era la guerra de Cuba y por no saber lo que era la fuerza de los Estados Unidos". ${ }^{15}$

13 Discurso pronunciado por Rafael M. ${ }^{\mathrm{a}}$ de Labra en el Congreso de los Diputados el 10 de julio de 1871 y que apareció publicado en el libro titulado: La Política colonial y la revolución española de 1868. (Discursos Notas y Referencias de 1868 a 1916). Madrid, Tipografía Sindicato de Publicidad, 1915, págs. 23-77.

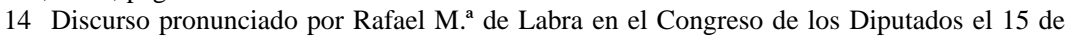
abril de 1880 y que apareció publicado con el título: "El primer Presupuesto de Cuba", en Discursos políticos, académicos y forenses. Madrid, Imprenta de Aurelio J. Alaria, 1884, págs. 31-43.

15 Morote, Luis: El Pulso de España. Madrid, Establecimiento Tipográfico de Ricardo Fe, 1904, págs. 165-174. 
Esta situación no había sido asumida nada más que por algunos autonomistas antillanos y otros republicanos peninsulares.

En la reflexión que Labra hacía se retrotraía hasta considerar que las reformas implantadas en América, a comienzos del siglo XIX, habían sido la causa de que Cuba y Puerto Rico no se hubieran independizado, al igual que el resto de las repúblicas sudamericanas (reformas del marqués de Sonora en 1775 y de las Cortes de Cádiz en 1812).

Sin embargo, esta política de reformas se vio bruscamente interrumpida con la real cédula de 1825 , que dio a los capitanes generales en las Antillas, aún en tiempo de paz, las facultades omnímodas de los jefes de plazas sitiadas en tiempo de guerra, el monopolio de los mercados antillanos para las harinas de Castilla y los géneros de Cataluña, junto con la expulsión de los diputados de Cuba, Puerto Rico y Filipinas en las Cortes de 1835; la política reaccionaria en 1865 , que concluiría con la separación de la República Dominicana, y un largo etcétera.

Por consiguiente, la crisis colonial e internacional del 98 no era una cuestión casual, sino una de las manifestaciones de la crisis general de la España Moderna:

"Ni en la Península, ni en las colonias podían producirse más que efectos de perdición, el centralismo, la dictadura más o menos intermitente, la mistificación sistemática de las libertades públicas, el clericalismo, el proteccionismo mercantil y la supeditación de las atenciones de la enseñanza pública y del presupuesto de paz a las exigencias de la burocracia y el militarismo". ${ }^{16}$

A raíz del desastre del 98 Rafael M. ${ }^{a}$ de Labra realizó importantes estudios donde analizó la situación de España. Su labor fue la de difundir a través de conferencias esta nueva circunstancia. En la titulada "El pesimismo de última hora" analizó la situación interna de España en comparación con la de otros países, a los que consideraba "naciones contemporáneas" y a los que llamaba a adoptar distintas reformas para salir de la crisis. Efectivamente, Labra está combatiendo el pesimismo del momento y lo hace con un discurso regeneracionista en el que apunta distintas soluciones para imprimir cierto dinamismo a la sociedad española.

Paralelamente inicia una crítica razonada del Tratado de París, que violaba las más elementales normas del Derecho internacional, poniendo de manifiesto la "ilegal" intervención de los Estados Unidos en la guerra hispano-cubana.

16 Labra, Rafael M.a.: El Congreso Hispano-Americano de 1900. Discurso. Madrid, Tipografía de Alfredo Alonso, 1901, págs. 44-50. 
La posición política de Labra después del 98 fue ofrecer un claro apoyo al partido republicano y defender públicamente cómo los únicos que podían "salvar a España de la anemia que padecía eran los republicanos al estar más capacitados moralmente y poner término al espectáculo que si continuara aumentaría las causas desmoralizadoras y destructoras de nuestro país". ${ }^{17}$

Ya en 1897 había pronunciado un discurso en el Teatro León mostrando sus simpatías hacia el partido Fusión Republicana y a la República española, "cuya causa sirvo desde 1873 sin haber rectificado en lo fundamental de mi doctrina política de $1870 " .{ }^{18}$

A pesar de que Labra mantuvo una posición firme frente a la independencia de Cuba, su labor fue reconocida por los cubanos de las diversas tendencias políticas. El 12 de diciembre de 1915 numerosos periódicos de La Habana recogieron la noticia sobre el cambio de nombre de la conocida calle del Aguila, por el de "Rafael María de Labra". Presidieron el acto solemne el general Freire Andrade, alcalde de La Habana; el ministro de España en Cuba, Sr. Mariátegui; el presidente de la República, representado por el secretario general del Gobierno, Rafael Montoro, y los ministros de Hacienda, Instrucción Pública y Negocios Extranjeros. Los promotores de esta iniciativa habían sido los principales representantes de la Fiesta de la Raza, y el diputado Juan Gualberto Gómez, fundador de la "Junta Suprema de Color".

En la Península aparecieron reseñas en El País, enviadas por Juan Gualberto Gómez, con el título: "Demostración trascendental en América", en la cual destacaba la campaña democrática, autonomista y abolicionista de Labra, aclamándole como uno de los hijos predilectos de Cuba por su contribución a la intimidad de los pueblos trasatlánticos. ${ }^{19}$ Decía Gómez: "Labra nunca ha sido revolucionario, permaneció siempre fiel a España, aunque esto no le impidió solicitar reformas para Cuba, tachándosele incluso en alguna época como desafecto a la soberanía española. Cuba estaba en deuda con él y ya la ha saldado". ${ }^{20}$

17 Labra, Rafael M. a: El Partido Republicano en España. Discurso pronunciado en el mitin de propaganda republicana en el Teatro de los Campos Eliseos de Gijón, el 15 de octubre de 1899. Madrid, Tipografía de Alfredo Alonso, 1900, págs. 30-31.

18 Labra, Rafael M.a: La Política colonial, pág 8.

19 Labra, Rafael M. ${ }^{\text {a: }}$ El Poder de las Ideas. Madrid, Establecimiento Tipográfico de Jaime Ratés, 1916, pág. 16.

20 Ibídem, págs. 39-40. 
También aparecieron artículos laudatorios en La Correspondencia de España de Madrid, llamándole "el más importante propagandista de la unión espiritual y material entre España y América, y patriota del americanismo en España"; en El Liberal, el $A B C$, en La Ilustración Española y Americana, El Popular de Málaga, El Noroeste de Gijón, El Naranco de Oviedo. Y en La Habana en La Noche, La Discusión, El Triunfo, El Heraldo de Cuba, etc.

La respuesta de Labra ante estos hechos fue bastante elocuente y llena de sinceridad, con frases como "esta iniciativa de la raza de color, que había sido levantada y dignificada por nuestras leyes abolicionistas y el concurso admirable de todos los negros y blancos españoles que vivían en la Gran Antilla". Los negros de otro tiempo que hoy se encontraban en posesión de todos los derechos políticos y sociales eran senadores, diputados, concejales, oradores, militares, publicistas, periodistas...

\begin{abstract}
"Yo siempre he tenido una posición franca frente al problema antillano. Comprometí mi honor asegurando la perfecta compatibilidad de la autonomía colonial con la integridad de la patria española. Creo sin vana modestia que esta garantía de mi persona sirvió para algo, para que las soluciones autonomistas, aparte de la abolición de la esclavitud, encontraran simpatías en algunos españoles dudosos o resistentes. Y cuando se perdieron las colonias yo no tuve que pensar donde estaba mi puesto. Me decidí silenciosamente, quebrantado y dolorido y en medio del respeto de todos, por la Nación ofendida y mal tratada por el Tratado de París de 1898.

No creo que hice una heroicidad. Pero tengo la convicción de que ningún español perdió entonces individualmente más que yo, que perdí mi bufete, mi posición parlamentaria y mi tranquilidad. Ningún insurrecto ha dudado jamás de mi lealtad a la bandera española. Pero yo no he ofendido nunca a los insurrectos. Los tenía por equivocados y reconocí honradamente la sinceridad de esto en mi último discurso en el Senado en $1896 " .{ }^{21}$
\end{abstract}

Labra sería reconocido como "El Embajador Moral de la América Libre". ${ }^{22}$

A modo de conclusión destacaremos las siguientes cuestiones. Rafael M. ${ }^{a}$ de Labra es, en el panorama político español de la segunda mitad del siglo XIX y comienzos del XX, uno de los intelectuales más preocupados por lo que se denominaba en la época "la cuestión colonial". Su actitud ante

21 Labra, Rafael M.a : El Poder de las Ideas, págs. 52-54.

22 Homenaje del Casino Español de La Habana. Labra, Rafael M. ${ }^{\text {a }}$ : El Poder de las ideas. Gran demostración cubana en favor de la Intimidad Hispano-Americana. La prensa de Cuba, América y España. Madrid. Establecimiento Tipográfico de Jaime Ratés, 1916, pág 52. 
los graves problemas en los que se encontraban sumidas las últimas colonias del imperio español, como eran la esclavitud, la intransigencia e intolerancia representada por la mayoría de los capitanes generales enviados a Cuba, a excepción de algunos entre los que podemos citar al general Domingo Dulce (depuesto de su mando en 1869 por los Cuerpos de Voluntarios), ${ }^{23}$ fue bastante clara y tajante ante una situación que debía ser transformada. De ahí la insistencia de Labra de ahondar en el análisis de la situación social, política y económica de las colonias.

A pesar de su posición tolerante, reformista y sus simpatías hacia los republicanos, Labra defendió, sin lugar a dudas, el sistema colonial imperante en la Europa del siglo XIX y en ningún momento puso en tela de juicio el sistema como tal. Ahora bien, debido a su voluntad democrática y conciliadora, no podía mantenerse impasible ante la situación de injusticia, desigualdad, ignorancia e intransigencia que padecían no sólo Cuba y Puerto Rico, sino también la propia sociedad en la metrópoli.

Debido a este deseo de Labra de transformar la realidad con su lucha infatigable por conseguir reformas políticas, sociales y económicas para las colonias, abogó por una política reformista; de ahí las alusiones en sus discursos en el Congreso y en el Senado a los intelectuales cubanos de tendencia reformista, entre los que citaba a José Antonio Saco, Francisco Frias y Jacott, conde de Pozos Dulces, y José Ramón Betancourt, los cuales fueron desterrados por las autoridades a mediados del siglo XIX, o en otros casos tomaron el camino del destierro voluntariamente hacia Nueva York, Madrid o París. ${ }^{24}$

Por ejemplo, Betancourt en 1873 pedía que se cumplieran las promesas de los revolucionarios del 68 sobre la abolición de la esclavitud. "Que no medien otros cuarenta años de fraudes legales". ${ }^{25}$

En realidad nos ha resultado bastante clarificadora para nuestro análisis la definición, dada por Elena Hernández, sobre lo que significaba el término "reforma" para estos liberal-radicales de la España de la segunda

23 La importancia del grupo de tendencia ultra conservadora conocido en Cuba como "Los Cuerpos de Voluntarios", controlados por los sectores más conservadores y españolistas, a cuya cabeza se encontraba el traficante negrero Julián Zulueta, y el papel que jugaron en Cuba durante la Guerra

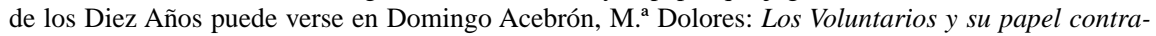
rrevolucionario en la Guerra de los Diez Años en Cuba, 1868-1878. París, 1997.

24 Domingo Acebrón, M. ${ }^{a}$ Dolores: "Los reformistas cubanos en París, a mediados del S. XIX". En Actas del Colloque International, Presence des Reformistes cubains en France et Espagne au milieu du XIX $X^{e}$ siècle. Madrid, 1998 (en prensa).

25 Mesa, Roberto: El colonialismo español en la crisis del XIX español. Madrid, 1990, pág. 81. 
mitad del XIX. Se centraba en la reforma social, mediante una educación laica e igual para todos; reforma económica, basada sobre todo en la liberalización de los intercambios y en la abolición de todo tipo de trabas proteccionistas, y reforma política, como medio de acabar con la corrupción del antiguo régimen. ${ }^{26}$

Haciendo gala de la coherencia que le caracterizara a lo largo de toda su vida, Labra colaboró y defendió con todos los medios a su alcance la abolición de la esclavitud, en Cuba y Puerto Rico, al considerarla como una de las lacras sociales fundamentales y que debía ser erradicada para el progreso social y político en las colonias.

A pesar de considerar los problemas inherentes al sistema colonial, no por eso apoyó en ningún momento los movimientos de independencia en Cuba, los cuales comienzan en 1868, con la Guerra de los Diez Años, continúan con la Guerra Chiquita, entre los años 1879-1881, y culminan con la última guerra de independencia, entre 1895-1898. Por el contrario, fue bastante crítico, aunque respetuoso, concediéndoles en algún momento parte de culpa en la paralización de las reformas.

La guerra del 68, Guerra de los Diez Años o movimiento cespedista, puesto que este fue iniciado por el abogado bayamés Carlos Manuel de Céspedes, estalla en Cuba después de un largo proceso social y político. Ejemplo que va desde las revueltas de esclavos, como la Conspiración de Aponte (1812), la Conspiración de la Escalera (1844), las conspiraciones masónicas de los Soles y Rayos de Bolivar (1822-1824) y del Aguila Negra, hasta el fracasado intento de los comisionados de Cuba y Puerto Rico en la famosa Junta de Información en 1866, los cuales vieron como todas sus peticiones eran denegadas, haciendo referencia una de las principales a la abolición de la esclavitud.

Labra no podía justificar la paralización de las reformas debido al estallido de la guerra, sino que por el contrario, y él mismo lo reconocerá en algunas ocasiones, la guerra del 68 se produce debido a la asfixia política y malestar social de la sociedad en Cuba y a la negativa de España a conceder reformas.

Por otra parte, Labra fue partidario del sistema político autonomista, puesto que de esta forma quedaba a salvo la "integridad del territorio"; es decir, un sistema por el que sin tener que desprenderse de las antiguas colo-

26 Hernández Sandoica, Elena: "Rafael M. ${ }^{a}$ de Labra y Cadrana (1841-1919): Una biografía política”. Revista de Indias, Madrid, enero-abril, 1994, vol. LIV, n. ${ }^{\circ}$ 200, pág. 110. 
nias del Imperio español, se concederían reformas políticas y sociales tendentes a mejorar la situación política de las mismas.

De mayor relieve es la intuición de Labra, que supo ver con bastante claridad lo que iba a suponer el naciente imperialismo norteamericano, siendo bastante crítico con la posición adoptada por Estados Unidos ante la guerra de 1898, y muy especialmente con lo que supuso el Tratado de París, para España y para la propia Cuba.

Ante una situación de cierta crisis en España después del 98, Labra se mostrará partidario de la necesidad de regenerar la sociedad española a través de la educación.

Sólo nos resta añadir la importancia de la talla intelectual de Rafael M. ${ }^{a}$ de Labra. Su posición sincera, tolerante y democrática ante la convulsa sociedad española del siglo XIX y su mirada hacia América, que favoreció, después de obtenida la independencia de Cuba y Puerto Rico, una cierta unión de los pueblos de uno y otro lado del Atlántico. 